\title{
PRODUÇÃO CONVENCIONAL x INTEGRADA EM PESSEGUEIRO cv. MARLI NA DEPRESSÃO CENTRAL DO RIO GRANDE DO SUL ${ }^{1}$
}

\author{
ROSELI DE MELLO FARIAS², JOSE LUIS DA SILVA NUNES ${ }^{3}$, CARLOS ROBERTO MARTINS ${ }^{4}$, DENIS SALVATI \\ GUERRA $^{3}$, CLAITON ZANINI ${ }^{5}$, GILMAR ARDUINO BETTIO MARODIN ${ }^{6}$
}

\begin{abstract}
RESUMO - A produção integrada de frutas procura reduzir o uso de agrotóxicos, eliminar produtos considerados perigosos para a saúde humana ou prejudicial para o meio ambiente e, ao mesmo tempo, fomentar as boas práticas de manejo agrícola. Assim, os sistemas de produção convencional (PC) e integrado (PI) de pêssegos da cv. Marli foram comparados em relação às principais práticas de manejo da planta e do solo, controle fitossanitário, aspectos econômicos, bem como à qualidade da fruta, objetivando estabelecer o sistema de Produção Integrada de Frutas de Caroço (PIFC) na Depressão Central-RS. Na área conduzida sob PI, foram utilizadas as práticas de acordo com o manejo preconizado pela Organização Internacional de Controle Biológico e no sistema de PC, aquelas de uso comum pelo produtor. A produção de pêssegos obtidas em ambos os sistemas não foi afetada. $\mathrm{Na}$ área de PI, houve menor número de frutas por planta quando comparada com a PC, entretanto, os pêssegos apresentaram maior tamanho e peso, não afetando a produção final. A classificação das frutas demonstrou que os pêssegos provenientes do sistema de PI são na maioria, pertencente à CAT I (diâmetro > $57 \mathrm{~mm}$ ), enquanto os do sistema PC são de CAT II (48 a 57 mm). Houve maior incidência de Grapholita molesta e Monilinia fructicola no pomar de pêssegos provenientes do sistema de PI. O monitoramento de pragas e o manejo de doenças proporcionaram uma sensível redução na aplicação de agroquímicos. De uma forma geral é possível produzir pêssegos de melhor qualidade, mantendo a produtividade com uma redução considerável no uso de agroquímicos.
\end{abstract}

Termos para indexação: Pêssego, qualidade dos frutos, manejo do solo, manejo da planta.

\section{CONVENTIONAL PRODUCTION X INTEGRATED PRODUCTION OF PEACHES 'MARLI' IN THE CENTRAL DEPRESSION OF RIO GRANDE DO SUL STATE}

\begin{abstract}
The integrated production of fruits with Pit tries to reduce the use of pesticides, to eliminate products considered dangerous for human health or harmful to the environment and, at the same time, encourage good agricultural practices. Therefore the objective of the present work was to compare conventional (CP) and integrated (IP) production systems of peaches cv. Marli, with regards to plant and soil management, diseases and pest control, economical aspects, as well as fruit quality, to warrant the integrate production of stone fruits system (IPSF) in the Central Depressão-region of the state of RS. In the area managed as IP, the practices were in agreement with the handling recommended by the International Organization of Biological Control and in the CP system, the grove was managed as common used by the grower. Peach production in both systems wasn't affected. In the IP area, there was smaller number of fruits per plant compared to the CP area, however the peaches were of greater size there was no effect on total yield per plant. The majority of peaches from the IP system were classified as CAT I fruit (diameter $>57 \mathrm{~mm}$ ) while most of the peaches from the CP system were classified as CAT II fruit (48 a $57 \mathrm{~mm}$ ). There was higher incidence of Grapholita molesta and Monilinia fructicola in the peaches orchard deriving from the IP system. Monitoring pest and diseases effectively reduced agrochemical application. In general it is possible to produce peaches of better quality, maintaining the yields and considerable reduction of the use of agrochemicals.
\end{abstract}

Index terms: Peach, Fruit quality, soils management, plant management.

\section{INTRODUÇÃO}

A área plantada com pessegueiros no Brasil é de aproximadamente 21.000 hectares. O estado do Rio Grande do Sul detem 58\% desta área, em torno de 12.000 hectares. A produção brasileira gira em torno de 130.000 toneladas/ano, da qual, mais de $40 \%$ é produzida no Rio Grande do Sul (Jornal da Fruta, 2002). Embora o consumo percapita de pêssegos no Brasil seja baixo, em torno de $0,25 \mathrm{~kg} / \mathrm{hab} / \mathrm{ano}$, comparado aos $5 \mathrm{~kg} /$ hab/ano de países como Itália, Espanha, França e Inglaterra, houve crescimento da demanda desta fruta. Em algumas regiões, como a de Porto Alegre, atingiu em 2000 cerca de 1 kg/hab/ano (Marodin \& Sartori, 2000).

Aliado ao aumento da demanda, cresceu o grau de exigência dos consumidores, o que tornou necessária uma nova postura do produtor para satisfazer os mercados. O consumidor tem se tornado cada vez mais exigente quanto à qualidade do produto final. Inicialmente buscavam-se frutas com bom calibre, boa aparência e características peculiares da cultivar. Embora nestes requisitos os produtos ainda deixem a desejar, o mercado passou a exigir novos atributos. Nesta nova fase, são contemplados aspectos ligados às características organolépticas, à segurança alimentar e à proteção ao ambiente. Isso contrasta com o sistema de produção praticado nos últimos tempos, com excesso no uso de insumos e pouca preocupação com o impacto ambiental (Martins et al., 2001).

A Produção Integrada de Frutas de Caroço (PIFC) apresentase como alternativa para a produção de frutas de qualidade, com a utilização de técnicas e práticas de forma integrada, com ênfase na redução de agroquímicos, priorizando métodos biológicos, culturais e físicos no controle de pragas e doenças, minimizando assim, os riscos de contaminação ambiental, preservando a saúde humana. Vários autores (Sansavini, 1998; Deckers, 2000; Fachinello et al., 2000; Molinari, 2001) relatam que o surgimento da Produção integrada de frutas (PIF) iniciou efetivamente nos anos 70, como uma extensão do "Manejo Integrado de Pragas" (MIP) e como uma necessidade de reduzir o uso de agrotóxicos e de preservar o ambiente.

O sistema já é amplamente empregado em vários países com resultados positivos, tornando-se rapidamente um pré-requisito para a comercialização de frutas em vários centros internacionais e, mais recentemente, no Brasil (Sanhueza, 2000).

Neste contexto, o objetivo principal deste trabalho foi comparar os sistemas de produção convencional, utilizado pelo produtor, com o preconizado pelas normas de produção integrada de pessegueiro, em relação às principais práticas agronômicas.

\footnotetext{
${ }^{1}$ (Trabalho 174/2002). Recebido: 26/09/2002. Aceito para publicação: 11/06/2003. Trabalho Realizado com apoio do MAPA/CNPq, Capes, UFRGS. Parte integrante da Dissertação Mestrado em Fitotecnia

${ }^{2}$ Eng $^{\mathrm{a}}$ Agr $^{\mathrm{a}}$ MSc. Prof ${ }^{\mathrm{a}}$ FZVA/PUCRS Campus II - Uruguaiana. 55 4118052, e-mail roselifarias@ bol.com.br

${ }^{3}$ Eng $^{\circ}$ Agr ${ }^{\circ}$ Pós Graduando em Fitotecnia, DHS/UFRGS, e-mail tobnunes@ig.com.br

${ }^{4} \mathrm{Eng}^{\mathrm{O}} \mathrm{Agr}^{\mathrm{O}} \mathrm{MSc}$. Pós Graduando em Agronomia, FAEM/UFPEL, 53 2757158, marticar@ ufpel.tche.br

${ }^{5}$ Bolsista de Iniciação Científica, Faculdade Agronomia/UFRGS, CNPq/Rhae

${ }^{6} \mathrm{Eng}^{\mathrm{o}} \mathrm{Agr}^{\circ}$ Dr Prof ${ }^{\circ}$ Faculdade Agronomia, UFRGS. Av. Bento Gonçalves 7712, C.P.776, Porto Alegre, RS e-mail marodin @ ufrgs.br
} 


\section{MATERIALEMÉTODOS}

O experimento foi realizado em um pomar comercial de pessegueiros, com 10 anos de idade, localizado no município de São Jerônimo, Depressão Central do RS, situado à latitude $30^{\circ} 05^{\prime} \mathrm{S}$ e longitude $51^{\circ} 39^{\prime}$ $\mathrm{W}$, altitude média de 50 metros. Utilizaram-se plantas da cultivar Marli, enxertadas sobre o porta-enxerto de pessegueiro Capdeboscq, conduzidos em sistema de vaso com espaçamento de 6,0 X 4,0 m. Dois pomares adultos de aproximadamente 1 ha cada um, distanciados 500 metros, foram conduzidos no sistema de produção integrado (PI) e no sistema convencional (PC). Em cada área foram escolhidas ao acaso 10 plantas para se proceder as avaliações.

$\mathrm{Na}$ PC prevaleceu o manejo e práticas culturais normalmente utilizadas pelo produtor e de acordo com sua opção, como segue: Tratamentos fitossanitários com calendário fixo; manejo do solo com grades nas linha; sem poda verde; raleio leve e sem monitoramento de pragas e doenças. Nesse sistema foram realizadas dez aplicações de fungicidas: captan, iprodione, fluatriofol, carbendazin, clorotalonil e tiofanato metilico. Foram realizadas sete aplicações de inseticidas: dimetoato, fenitrotiom clorpirifós e phosmet. Na PI foram aplicadas as práticas recomendadas nas Normas de Produção Integrada de Frutas de Caroço (NPIFC), Versão 1 (Fachinello \& Herter, 2000), onde prevalece o manejo do solo com a cobertura vegetal com aveia nas entre linhas, aplicação única de herbicida pós-emergente na linha (com princípio ativo de glifosate ou glufosinato de amônio), adubação das plantas realizada com base na análise do solo e análise foliar respeitando os limites máximos de fertilizantes químicos, principalmente os nitrogenados. Na poda hibernal foram retirados poucos ramos, eliminando aqueles voltados para o centro da planta, ramos doentes e os atacados por cochonilhas ou em excesso. Nos locais de corte de ramos com diâmetro superior a $3 \mathrm{~cm}$ foi feito tratamento com pasta fúngica (tinta plástica e cobre). Não se realizou o desponte dos ramos remanescentes. A poda verde ocorreu aproximadamente 15 dias antes da colheita, retirando-se os ramos nos quais o crescimento estava dirigido para o interior da copa ou muito próximos às frutas. Em meados de outubro, aproximadamente 40 dias após a plena florada, foi realizado manualmente o raleio das frutas, procurando deixar um espaço mínimo de $10 \mathrm{~cm}$ e retirando as frutas da extremidade dos ramos.

O manejo e monitoramento para controle de doenças foram realizados levando-se em conta os estádios fenológicos do pessegueiro (mais suscetíveis a determinados patógenos), as condições climáticas antes e após a aplicação do produto e o histórico da disponibilidade de inóculo da área. Neste sistema foram realizados seis aplicações de fungicidas: captan e iprodione. Sendo três aplicações com inseticidas: fenitrotion, dimetoato (isca tóxica) e triclorfom.

O manejo das pragas como a mariposa oriental (Grapholita molesta) foi avaliado nas áreas de PI e da PC, por meio do monitoramento de duas armadilhas/área, modelo delta contendo o feromônio sexual sintético, com contagem do número de machos capturados semanalmente. A mosca-das-frutas (Anastrepha fraterculus) foi monitorada colocando-se em cada área experimental duas armadilhas tipo Mc-Phail contendo suco de uva a 30\% e avaliada semanalmente. Os ácaros fitófagos (Panonychus ulmi e Tetranychus urticae) foram monitorados através de avaliações visuais dos sintomas de ataque em toda a área experimental.

O período de colheita estendeu-se de 01 a 20 de dezembro, totalizando 6 repasses na PI e de 06 a 20 de dezembro, com 5 repasses na PC. Em cada colheita foram realizadas avaliações de produção (número e peso expressos em $\mathrm{kg} /$ planta), classificação (determinada pelo tamanho (calibre) em três categorias: pêssegos com diâmetro superior a $57 \mathrm{~mm}$ foram definidos como CAT I, com diâmetro entre 57 e 48 mm como pêssegos de CAT II e diâmetro inferior a $48 \mathrm{~mm}$ pertencentes a CAT III), qualidade e danos nas frutas produzidas em ambos os sistemas (realizada pela contagem do número de frutas com sintomas de podridão parda, tanto no solo como na planta; atacadas por grafolita e mosca-das-frutas; outras podridões, bacteriose, ferrugem, antracnose e sarna e injúrias nas frutas como rachaduras e batidas). Todos os dados foram transformados em $\%$.

$\mathrm{O}$ delineamento experimental utilizado foi o inteiramente casualizado, com 10 repetições, sendo cada planta uma unidade experi- mental. Os dados foram submetidos à análise de variância e a comparação de médias pelo Teste $t(\mathrm{P} \leq 0,05)$. As análises das variáveis estudadas foram executadas pelo programa SANEST.

\section{RESULTADOSE DISCUSSÃO}

A produção de pêssegos não foi afetada pelos sistemas de produção, mas as frutas provenientes da área da PI apresentaram maior peso médio, resultado da menor carga de frutas por planta (Tabela 1). Ressalta-se que os princípios da Produção Integrada não contemplam a maximização da produtividade, mas sim a produção de frutas de qualidade, promovendo a preservação do ambiente e o respeito à saúde do consumidor e do próprio produtor, de maneira a manter a sustentabilidade da atividade. O maior peso das frutas obtido na PI deve-se a menor quantidade de frutas por planta e uma maior relação folha/fruta, conseqüentemente uma menor quantidade de frutas competindo por fotoassimilados, o que é comum para praticamente todas as frutíferas.

TABELA 1 - Produção de pêssegos em pomar conduzido nos sistemas convencional (PC) e integrada (PI). São Jerônimo/RS, 2000.

\begin{tabular}{c|c|c|c}
\hline $\begin{array}{c}\text { Sistemas de } \\
\text { produção }\end{array}$ & $\begin{array}{c}\text { Produção por } \\
\text { planta (kg) }\end{array}$ & $\begin{array}{c}\text { Número de } \\
\text { frutos por } \\
\text { planta }\end{array}$ & $\begin{array}{c}\text { Peso médio dos } \\
\text { frutos/planta } \\
(\mathrm{g})\end{array}$ \\
\hline PC & $49.6 \mathrm{a}^{*}$ & $577 \mathrm{a}$ & $88,8 \mathrm{~b}$ \\
PI & $39.9 \mathrm{a}$ & $390 \mathrm{~b}$ & $103,8 \mathrm{a}$ \\
\hline
\end{tabular}

*Médias seguidas da mesma letra não diferem significativa pelo teste a $5 \%$.

A intensidade de coloração vermelha na epiderme nas frutas conduzidas em ambos os sistemas de produção não apresentaram diferenças significativas (dados não apresentados). A variação da coloração depende do grau de maturação e da cultivar. A mudança de coloração da epiderme, observada durante a maturação das frutas, é o principal critério utilizado pelo consumidor para julgar o estádio de maturação e a qualidade aparente (Martins, 2001). Assim, os pigmentos da epiderme do pêssego são importantes, pois a preferência pela cor de uma fruta está associada a aspectos culturais do consumidor (Vendrell \& Carrasquer, 1994). Segundo estes autores esta característica é fortemente influenciada por fatores edafoclimáticos como luz solar, temperatura e exposição das frutas à luz, além de práticas como a poda e o raleio, porém essas diferenças na pigmentação não foram verificadas em ambos os sistemas em relação à cor.

As frutas do sistema de PI apresentaram superioridade quanto ao calibre, decorrente principalmente da maior intensidade da prática do raleio, proporcionando condições de menor competitividade por fotoassimilados, promovendo o maior crescimento das frutas remanescentes. Verifica-se que $62,66 \%$ dos pêssegos produzidos sob o sistema de PI pertence a CAT I, 36,91\% das frutas a CAT II e apenas 0,43\% das frutas a CAT III. Os pêssegos produzidos sob o sistema de PC tiveram a maioria das frutas, $51,51 \%$, pertencentes a CAT II (Figura 1).

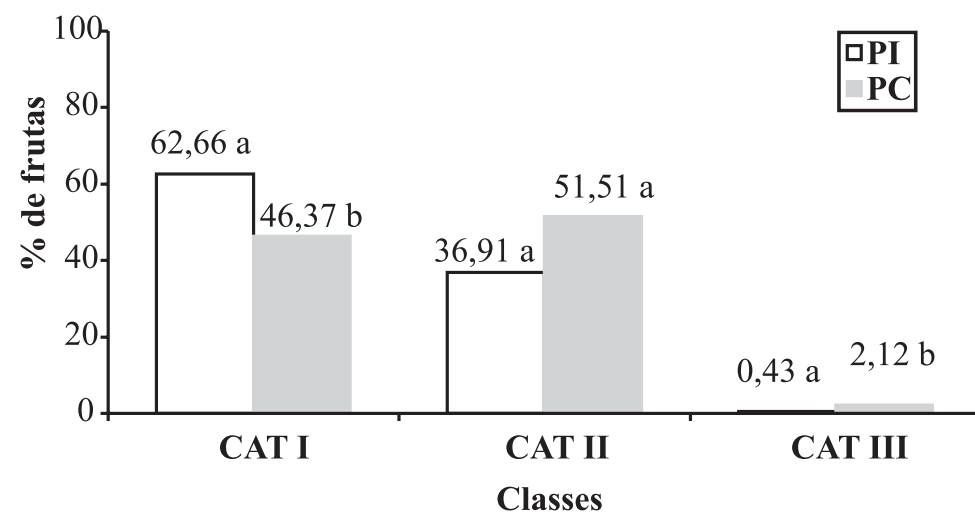

FIGURA 1 - Percentagem de pêssegos da cv. Marli, nas diferentes categorias: CAT I $(\geq 57 \mathrm{~mm})$, CAT II ( 57 a $48 \mathrm{~mm})$ e CAT IIII $(\leq 48$ $\mathrm{mm})$, nos sistemas de Produção Integrada (PI) e Produção Convencional (PC). São Jerônimo/RS, 2000. 
A intensidade de danos ocasionados por pragas e doenças foi significativamente maior em pêssegos produzidos no pomar conduzido sob sistema de PI, comparados com o sistema de PC, sendo o ataque de pragas o fator determinante no aumento de danos às frutas da PI. A principal praga responsável pelos danos foi a grafolita (Grapholita molesta), que atacou com maior intensidade o pomar da área da PI. Isto se deve a uma falha de manejo onde o produtor não fez uma aplicação no momento adequado, pouco antes da colheita. Quanto aos danos ocasionados por moléstias, não houve diferença significativa entre os sistemas, sendo que a podridão parda (Monilinea fructicola) foi responsável pelos maiores índices de danos às frutas (Figura 2).

Os demais danos avaliados nas frutas, como Xanthomonas, sarna, mosca-das-frutas, rachaduras e danos mecânicos, não foram constatadas diferenças significativas ocasionados nos pêssegos provenientes de ambos os sistemas (Figura 2).

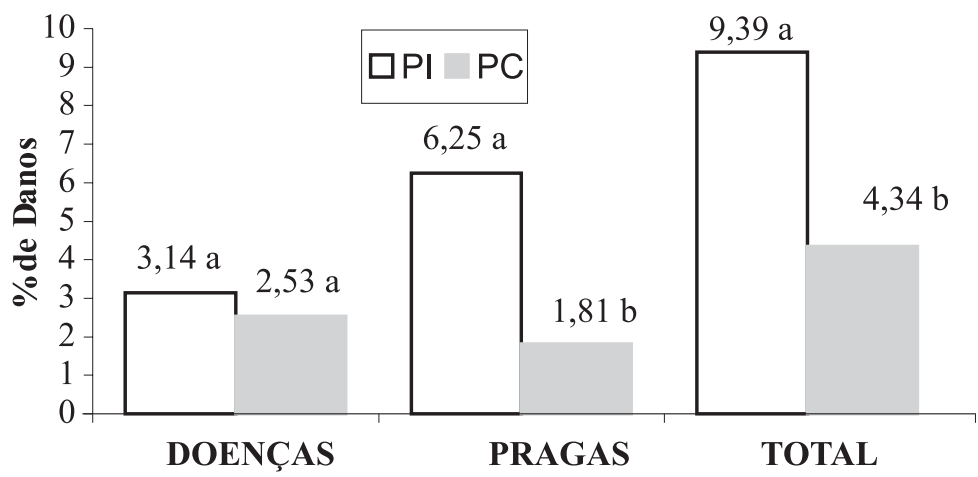

FIGURA 2 - Percentagem de danos em pêssego da cv. Marli, decorridos de doenças e pragas nos sistemas de Produção Integrada (PI) e Produção Convencional (PC). São Jerônimo/RS, 2000. Médias seguidas da mesma letra não diferem significativamente pelo teste $\mathrm{t}$ a $5 \%$.

No pomar conduzido sob o sistema de PI, as plantas receberam menor número de aplicações de agroquímicos do que às do pomar sob o sistema convencional, determinando assim frutas com um menor risco de contaminação e menor impacto ambiental (Figura 3). Das nove intervenções químicas feitas no pomar conduzido sob o sistema de PI, três aplicações foram com inseticidas utilizados no controle de grafolita e seis aplicações com fungicidas, principalmente para o controle de doenças como podridão parda. Na área da PC foram realizadas sete aplicações com inseticidas e nove com fungicidas.

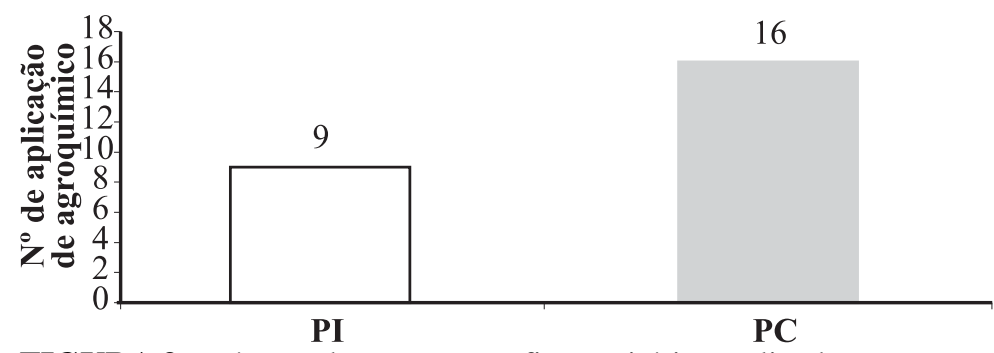

FIGURA 3 - Número de tratamentos fitossanitários realizados em pessegueiros da cv. Marli, conduzidos sob os sistemas de Produção Integrada (PI) e Produção Convencional (PC). São Jerônimo/RS, 2000.

Assim, com a utilização da PI é possível oferecer à sociedade pêssegos com qualidade, respeitar o ambiente, diminuir riscos ao produtor e ao consumidor. Além disso, permite que se faça a rastreabilidade do sistema de produção das frutas em todo seu ciclo, uma vez que tudo é registrado em Caderneta de Campo (Fachinello et al., 2001). No entanto, ressalta-se a necessidade de condução e acompanhamento de outros estudos no decorrer das safras a fim de validar o sistema para que assim possa ser recomendado e empregado pelos produtores sem maiores riscos econômicos para o empreendimento frutícola.

\section{CONCLUSÕES}

No primeiro ano de observação foi possível obter na área da PI produção similar ao manejo convencional do produtor e um aumento no peso médio dos frutos. O monitoramento de pragas e moléstias é uma ferramenta eficaz de manejo, proporcionando redução da utilização de agroquímicos.

\section{REFERÊNCIASBIBLIOGRÁFICAS}

DECKERS, T. Plant management in integrated fruit production. In: SEMINÁRIO BRASILEIRO DE PRODUÇÃO INTEGRADA DE FRUTAS, 2., Bento Gonçalves, 2000. Anais... Bento Gonçalves: Embrapa Uva e Vinho, 2000. p. 20-29.

FACHINELLO, J. C.; HERTER, F. G. Diretrizes para produção integrada de frutas de caroço. Pelotas: Embrapa Clima Temperado, 2000. 46p. (Circular Técnico, 19).

FACHINELO, J. C.; GRUTZMACHER, A. D.; HERTER, F. G.; CANTILLANO, F.; MATTOS, M. T.; FORTES, J.F.; AFONSO, A. P.; TIBOLA, C. S. Avaliação do sistema de produção integrada de pêssego de conserva na região de pelotas-safra 1999/2000. In: SEMINÁRIO SOBRE PRODUÇÃO INTEGRADADE FRUTAS, 2., 2000, Bento Gonçalves, Anais... Bento Gonçalves, RS:Embrapa Uva e vinho, 2000. p. 78-85.

FACHINELLO, J. C.; GRUTZMACHER, A. D.; FARIA, J.L. C.; HERTER, F. G.; FORTES, J. F.; AFONSO, A. P. S.; TIBOLA, C. S. Avaliação agronômica de um pomar de pessegueiro conduzido no sistema de produção integrada. Revista Brasileira de Fruticultura, Cruz das Almas, v.23, n.1, p.138-142, 2001.

JORNAL DA FRUTA. Situação da safra 2000/01 e previsão da safra 2001/02 de frutas de clima temperado. Junho de 2002. pg 6.

MARODIN, G. A. B.; SARTORI, I. A.; Situação das frutas de caroço no Brasil e no mundo. In: SIMPÓSIO INTERNACIONAL DE FRUTAS DE CAROÇO: PÊSSEGOS, NECTARINAS EAMEIXAS,1., 2000, Porto Alegre. Anais....Porto Alegre: UFRGS - DHS, 2000.p. 7-16.

MARTINS, C. R. Qualidade pós-colheita de pêssegos em pomar cultivado com aveia. 2001. 70f. Dissertação (mestrado em Agronomia Fruticultura) - Faculdade de Agronomia Eliseu Maciel - Universidade Federal de Pelotas, Pelotas, 2001.

MARTINS, C. R.; CANTILLANO, R. F. F.; TREPTOW, R.; FONSECA, R. M.; ROMBALDI, C. V. Manejo da Cobertura Vegetal na Conservação e Qualidade Pós-colheita de Pêssegos (Prunus persica (L.) Batsch) cv. Chimarrita. Revista Brasileira de Fruticultura, Cruz das Almas, v.23, n. 1, p. 55-58, 2001.

MOLINARI, F. La difesa dal fitofagi nella produzione integrata del pesco in Itália. In: SEMINÁRIO SOBRE PRODUÇÃO INTEGRADA DE FRUTAS, 3., Bento Gonçalves, 2001. Anais... Bento Gonçalves, RS: Embrapa Uva e Vinho, 2001. p. 48-58

SANHUEZA, R. M. V. Outras estratégias de pesquisa e desenvolvimento na produção integrada de frutas. In: SEMINÁRIO SOBRE PRODUÇÃO INTEGRADA DE FRUTAS, 2., 2000, Bento Gonçalves, Anais... Bento Gonçalves, RS:Embrapa Uva e Vinho, 2000. p. 60-63.

SANSAVINI, S. Dalla produzione integrata alla "Qualità Totale" della frutta. Revista di Frutticoltura, Bologna, n.3, p.13-23, 1995.

SANSAVINI, S. Integrated fruit production: process, issues, propsects after ten years' experience. In: CONGRESSO BRASILEIRO DE FRUTICULTURA, 15., 1998, Poços de Caldas, MG. Anais... 17 p.

SARTORI, A. S. Aplicação de auxinas e incisão anelar em pessegueiro cv. Diamante. 2001, 111f. Dissertação (mestrado em Fitotecnia Horticultura) Universidade Federal do Rio Grande do Sul, Porto Alegre, 2001.

VENDRELL, M.; CARRASQUER, A. M. Fisiologia postcosecha de frutos de hueso. In: VENDRELL, M.; AUDERGON, J. M. Calidad PostCosecha y Productos Derivados en Frutos de Hueso. Lleida, Espanha, 1994. p. 37-55. 